\title{
The mediating effects of childhood neglect on the association between schizotypal and autistic personality traits and depression in a non-clinical sample
}

\author{
Jianbo Liu', Jingbo Gong ${ }^{2}$, Guanghui $\mathrm{Nie}^{3}$, Yuqiong He${ }^{1}$, Bo Xiao ${ }^{1}$, Yanmei Shen ${ }^{1}$ and Xuerong Luo ${ }^{1 *}$
}

\begin{abstract}
Background: Autistic personality traits (APT) and schizotypal personality traits (SPT) are associated with depression. However, mediating factors within these relationships have not yet been explored. Thus, the focus of the current study was to examine the effects of childhood neglect on the relationship between APT/SPT and depression.

Methods: This cross-sectional study was conducted on first-year students $(N=2469)$ at Hunan University of Chinese Medicine and Hengyang Normal College (Changsha, China). Participants completed surveys on APT, SPT, childhood neglect, abuse and depression.

Results: Through correlational analyses, APT and SPT traits were positively correlated with childhood neglect and depression $(p<0.05)$. In a hierarchical regression analysis, among types of childhood maltreatment, emotional neglect $(\beta=0.112, p<0.001)$ and physical neglect $(\beta=0.105, p<0.001)$ were the strongest predictors of depression. Childhood neglect did not account for the relationships between APT/SPT and depression. Further analysis found that childhood neglect mediated the relationship between SPT and depression but not APT and depression.

Conclusions: Among types of childhood maltreatment, neglect was the strongest predicting factor for depression. Neglect did not account for the relationship between APT/SPT and depression but was a strong mediating factor between SPT and depression.
\end{abstract}

Keywords: APT, SPT, Neglect, Depression, Mediating factor

\section{Background}

According to the Diagnostic and Statistical Manual, autism spectrum disorder (ASD) and schizophrenia spectrum disorder (SPD) are categorized into two different neuronal development disorders. However, studies found overlap between ASD and SPD, including accompanying depression symptoms [1, 2]. Depression has been reported as the highest comorbid symptoms with ASD [3]. Matson et al. [3] reported that 30\% of those diagnosed with ASD are also diagnosed with depression [4].

\footnotetext{
* Correspondence: luoxuerong@csu.edu.cn

${ }^{1}$ Mental Health Institute of The Second Xiangya Hospital and Key Laboratory of Psychiatry and Mental Health of Hunan Province, The Central South University, Changsha 410000, China

Full list of author information is available at the end of the article
}

Onwuameze et al. [2] reported rates of depression that ranged from $18 \%-41 \%$ in the different assessment periods for SPD. Prior research has shown that ASD and SPD are both correlated with dysregulation of the hypothalamicpituitary-adrenal (HPA) axis, which may also be linked to depression [5, 6]. Additionally, some genes associated with an increased risk of SPD and APD also increase the risk of suffering from depression. For example, MTHFR gene C667T polymorphism increases the risk of autism [7] and also increases the risk of depression [8]. Similarly, the COMT gene rs4680 increases the risk of SPD [9] and also increases the risk of depression [10].

Recent research found that autistic personality traits (APT) and schizotypal personality traits (SPT) not only exist in ASD and SPD but also as 
subclinical psychiatric symptoms in the general population. APT are characterized by social and communication issues as well as restricted, repetitive and stereotyped patterns of behavior, interests and activities [11]. SPT include magical thinking, odd or bizarre behavior, and abnormal perceptual experiences and are considered one of the possible traits of a latent vulnerability to psychosis (schizotypy traits) [12].

Research has shown an overlap between APT and SPT [13] and found that significant positive correlations exist between APT/SPT and depression symptoms [14-16]. However, the confounding factors between APT/SPT and depression have not yet been identified. Therefore, the current study focused on the influence of several factors to better understand the association between APT/ SPT and depression.

Childhood neglect includes both emotional and physical neglect by guardians, causing harm to a child's health and/or development [17]. The prevalence of childhood neglect is greater than any other childhood maltreatment [18]. Neglect not only causes economic losses [19], but also increases the risk of criminality [20] and psychiatric illnesses such as depression [21]. Moreover, one study found that depression severity in orphans is related more strongly to neglect than abuse [22]. Interestingly, MRI studies have found that childhood neglect is associated with reduced brain volume in the regions of the brain responsible for memory function [23].

The risk of childhood abuse and neglect is greater among children and adolescents with disabilities [24-26]. Since APT and SPT are often diagnosed in childhood [27, 28], individuals with APT and SPT may experience more childhood neglect compared to healthy individuals due to communication problems and limited social skills [11]. In fact, research has found an association between childhood neglect and SPT. For example, Berenbaum et al. [29] found that neglect was most strongly associated with schizotypal symptoms among different forms of childhood maltreatment. However, to date, no studies have found an association between neglect and APT. According to a study by Sullivan et al. [25], people diagnosed with ASDs are at an increased risk of childhood neglect. Therefore, it is likely that there is an increased risk of neglect in participants with APT.

Based on the prior research described above, we formulated three hypotheses: (1) that a strong link would exist between APT/SPT and neglect, (2) that of all childhood maltreatments, childhood neglect would be the strongest predicting factor for depression and (3) that childhood neglect would be a mediating factor between APT/SPT and depression.

\section{Method}

\section{Participants}

A paper-and-pencil survey was administered to 2757 first-year college students (758 males and 1989 females) studying clinical medicine, nursing, psychology and education at Hunan University of Chinese Medicine and Hengyang Normal College (Changsha and Hengyang, China). The survey was administered during school hours with no time constraints. Surveys with more than $10 \%$ missing data were omitted from the analysis. The final analysis was obtained from a sample size of 2469 participants (684 males and 1785 females). The average age of the participants was $18.76 \pm 1.12$ years. There was no significant age difference between males and females. The prevalence of childhood abuse was evaluated according to the methodology of Bernstein (1997) [30]. The Ethics Committee of the Second Hospital of Hunan University of Chinese Medicine approved the study. Table 1 displays the demographic characteristics of the participants.

\section{Measures \\ Autism spectrum quotient ( $A Q$ )}

The AQ is a 50 -item self-rated questionnaire measuring autistic personality trait in intellectually normal

Table 1 Demographic characteristics of the students in the study $(N=2469)$

\begin{tabular}{lll}
\hline Variables & & Frequency (\%) \\
\hline Gender & Male & $684(27.7 \%)$ \\
& Female & $1785(72.3 \%)$ \\
Family status & Only-child family & \\
& Not only-child family & $819(33.17 \%)$ \\
Parents' marital status & $1650(66.83 \%)$ \\
& Completed families & \\
& Unmarried & $1936(78.41 \%)$ \\
& Others & $529(21.43 \%)$ \\
Monthly family income per person & $4(0.16 \%)$ \\
& $<1000$ yuan & \\
1000-1449 yuan & $825(33.41 \%)$ \\
$\geq 1500$ yuan & $467(18.91 \%)$ \\
The prevalence of childhood trauma & $1177(47.68 \%)$ \\
Emotional abuse & \\
Physical abuse & $128(5.18 \%)$ \\
Sexual abuse & $229(9.28 \%)$ \\
Emotional neglect & $237(9.60 \%)$ \\
Physical neglect & $341(13.81 \%)$ \\
\hline
\end{tabular}

Note: "Unmarried" includes divorced and widowed, "Other" includes missing data 
adults [31]. Each item on the AQ is scored on a 4point scoring system ranging from "strongly agree" to "strongly disagree". Each item was rated as "1" or "0"; hence 50 was the highest attainable AQ total score [31]. Higher scores indicated a greater number of autistic personality traits. In Mainland China, the AQ total has an internal consistency of 0.806 and testretest reliability has been recorded as 0.89 (Pearson's r correlation coefficient) [32].

\section{Schizotypal personality questionnaire (SPQ)}

The SPQ is a 74-item self-rated questionnaire measuring SPD (positive symptoms, negative symptoms and disorganized symptoms) [33]. The SPQ is a dichotomous item questionnaire (yes or no) and each item is scored as 1 (yes) or 0 (no); hence 74 is the highest SPQ score and higher scores indicate severe SPD. A Chinese Taiwan version of the SPQ has been developed [34]. The internal consistency of the SPQ total score is 0.90 in adults and 0.93 in adolescents.

\section{Childhood trauma questionnaire-short form (CTQ-SF)}

The CTQ-SF [35] is a 28-item self-rated questionnaire that measures the incidence of five types of childhood maltreatment: emotional abuse (EA), physical abuse (PA), sexual abuse (SA), emotional neglect (EN) and physical neglect (PN).

The CTQ is the most commonly used questionnaire to measure incidence of childhood abuse and neglect. The CTQ has proved to be a reliable and valid screening tool [35]. The items are rated on a 5-point scale ranging from 1 ("never true") to 5 ("very often true"). The score for each trauma therefore ranges from 5 to 25 with higher scores indicating greater trauma severity.

A Chinese version of CTQ-SF has been developed [36]. The Cronbach's alpha coefficients for the subscales of the Chinese version of the CTQ-SF range from 0.51 to 0.71 and the test-retest correlations range from 0.68 to 0.82 , except for physical neglect which has a testretest correlation of 0.43 .

\section{The Zung self-rating depression scale (SDS)}

The SDS, designed by Zung in 1965, is a 20 -item selfreport questionnaire that measures depressive symptoms [37]. The SDS is a suitable and common questionnaire that measures depression symptoms among adults. Higher scores indicate greater severity of depression symptoms. The correlation between each item and SDS total was greater than 0.5 in Chinese college students [38].

\section{Statistical analysis}

Data analyses were conducted using SPSS version 21 and AMOS version 22 statistical software (IBM, Armonk, NY). Correlation analyses were performed to test the relationships among $\mathrm{SPQ}, \mathrm{AQ}$, abuse, neglect and depression. A hierarchical regression model was used to test the predicting strength of APT/SPT total on depression after controlling for gender, abuse and neglect. A mediation model with bootstrapping method (a bootstrap sample of 2000 was specified) was used to assess indirect effects of neglect [39]. The indirect model was used since the bootstrapping confidence intervals did not include zero [40]. In addition, the Chi-squared test $(p>0.05)$, the Goodness-of-Fit Index (GFI, $>0.90)$, the Adjusted Goodness-of-Fit Index (AGFI, >0.90), the Root-Mean-Square Error of Approximation (RMSEA, $<0.06)$ and the Comparative Fit Index $(\mathrm{CFI},>0.95)$ were used to evaluate the mediation model $[41,42]$.

\section{Results}

Descriptive statistics and correlation

Correlation analyses found that AQ total, SPQ total, abuse and neglect were positively related to depression (all $p$ values $<0.01)$, and that AQ total and SPQ total were positively related to neglect and abuse $(p<0.01)$ (Table 2).

\section{APT/SPT predicted depression after controlling for gender, abuse and neglect}

The hierarchical regression model was significant after gender was entered in step 1 and SPQ total was entered in step $2\left(\Delta \mathrm{R}^{2}=0.233, \mathrm{~F}_{1}, 2466=748.606, p<0.001\right)$. SPQ total was an independent predictor for depression $(\beta=$ $0.485, p<0.001$ ) (see Table 3). The AQ total was entered in step 3 and this model was also significant $\left(\Delta R^{2}=\right.$ $\left.0.022, \mathrm{~F}_{1}, 2465=71.919, p<0.001\right)$. SPQ total $(\beta=0.416$, $p<0.001)$ and AQ total $(\beta=0.162, p<0.001)$ were independent predictors for depression (see Table 3).

Table 2 Descriptive statistics and the correlation for study measure $(n=2469)$

\begin{tabular}{llllllllr}
\hline & $\begin{array}{l}\text { SPQ } \\
\text { total }\end{array}$ & $\begin{array}{l}\text { AQ } \\
\text { total }\end{array}$ & EA & PA & SA & EN & PN & Depression \\
\hline SPQ total & 1.00 & & & & & & & \\
AQ total & $.419^{* *}$ & 1 & & & & & & \\
EA & $.376^{* *}$ & $.143^{* *}$ & 1 & & & & & \\
PA & $.238^{* *}$ & $.085^{* *}$ & $.578^{* *}$ & 1 & & & & \\
SA & $.267^{* *}$ & $.090^{* *}$ & $.523^{* *}$ & $.617^{* *}$ & 1 & & & \\
EN & $.197^{* *}$ & $.114^{* *}$ & $.449^{* *}$ & $.431^{* *}$ & $.321^{* *}$ & 1 & & \\
PN & $.236^{* *}$ & $.085^{* *}$ & $.469^{* *}$ & $.424^{* *}$ & $.397^{* *}$ & $.591^{* *}$ & 1.00 & \\
Depression & $.484^{* *}$ & $.337^{* *}$ & $.342^{* *}$ & $.262^{* *}$ & $.287^{* *}$ & $.305^{* *}$ & $.317^{* *}$ & 1 \\
Mean (total) & 25.40 & 22.18 & 7.28 & 6.21 & 5.76 & 9.56 & 7.54 & 37.66 \\
SD (total) & 12.79 & 5.32 & 2.63 & 2.47 & 2.09 & 4.15 & 2.93 & 7.95 \\
Mean (male) & 27.48 & 22.22 & 7.48 & 6.95 & 6.41 & 10.14 & 8.15 & 38.17 \\
SD (male) & 14.17 & 4.88 & 2.94 & 3.27 & 2.98 & 4.52 & 3.33 & 8.52 \\
Mean (female) & 24.61 & 22.16 & 7.20 & 5.93 & 5.50 & 9.33 & 7.30 & 37.46 \\
SD (female) & 12.13 & 5.48 & 2.49 & 2.03 & 1.55 & 3.98 & 2.73 & 7.71 \\
\hline
\end{tabular}

${ }^{* *}<0.01 E A$ emotional abuse; $P A$ physical abuse; $S A$ sexual abuse; $E N$ emotional neglect; $P N$ physical neglect 
Table 3 Hierarchical regression model of predictors of depression $(n=2469)$

\begin{tabular}{|c|c|c|c|c|}
\hline & Adjusted $\mathrm{R}^{2}$ & $\Delta R^{2}$ & $\beta$ & $P$ \\
\hline Step 1 & 0.001 & 0.002 & & \\
\hline Gender & & & -0.04 & 0.047 \\
\hline Step 2 & 0.233 & 0.233 & & \\
\hline Gender & & & 0.009 & 0.629 \\
\hline SPQ total & & & 0.485 & $<0.001$ \\
\hline Step 3 & 0.255 & 0.022 & & \\
\hline Gender & & & 0.003 & 0.882 \\
\hline SPQ total & & & 0.416 & $<0.001$ \\
\hline AQ total & & & 0.162 & $<0.001$ \\
\hline Step 4 & 0.296 & 0.042 & & \\
\hline gender & & & 0.028 & 0.110 \\
\hline SPQ total & & & 0.336 & $<0.001$ \\
\hline AQ total & & & 0.167 & $<0.001$ \\
\hline EA & & & 0.115 & $<0.001$ \\
\hline PA & & & 0.045 & 0.053 \\
\hline SA & & & 0.100 & $<0.001$ \\
\hline Step 5 & 0.321 & 0.025 & & \\
\hline Gender & & & 0.037 & 0.032 \\
\hline $\mathrm{SPQ}$ total & & & 0.33 & $<0.001$ \\
\hline AQ Total & & & 0.162 & $<0.001$ \\
\hline EA & & & 0.051 & 0.026 \\
\hline PA & & & 0.001 & 0.974 \\
\hline SA & & & 0.087 & $<0.001$ \\
\hline EN & & & 0.112 & $<0.001$ \\
\hline PN & & & 0.105 & $<0.001$ \\
\hline
\end{tabular}

$B$ standardized regression coefficient; $E A$ emotional abuse; $P A$ physical abuse; $S A$ sexual abuse; $E N$ emotional neglect, $P N$ physical neglect

At step 4, variables of abuse were entered and the model was again significant $\left(\Delta \mathrm{R}^{2}=0.042, \mathrm{~F}_{3}, 3462=\right.$ 48.617, $p<0.001)$. SPQ total $(\beta=0.336, p<0.001)$, AQ total $(\beta=0.167, p<0.001)$, emotional abuse $(\beta=$ $0.115, p<0.001)$ and sexual abuse $(\beta=0.1, \mathrm{p}<0.001)$ were identified as independent predictors for depression (see Table 3).

At step 5, neglect variables were entered and this model was also significant $\left(\triangle R^{2}=0.025, F_{2}, 2460=45.967\right.$, $p<0.001)$. Neglect did not alter the relationship between $\mathrm{AQ} / \mathrm{SPQ}$ and depression, indicating that neglect does not account for the relationship between $A Q / S P Q$ and depression. However, SPQ total $(\beta=0.33, p<0.001)$ and AQ total $(\beta=0.162, p<0.001)$ remained independent predictors for depression.

Neglect (emotional neglect: $\beta=0.112, \quad p<0.001$; physical neglect: $\beta=0.105, p<0.001)$ was the strongest predictor of depression among all childhood maltreatments (see Table 3).

\section{Mediation analysis between $\mathrm{SPQ} / \mathrm{AQ}$ and depression}

One objective of the current research was to test the hypothesis that childhood neglect mediates the relationship between autistic or schizotypal personality traits and depression. However, there was no relationship between AQ total and neglect $(p>0.05)$ thus indicating that childhood neglect is not a mediator between autistic personality traits and depression. Therefore we excluded the relationship between AQ total and neglect in further analyses.

The estimated standardized regression coefficients for the effect of AQ total, SPQ total and neglect on depression were $0.16,0.33$ and 0.29 , respectively (all $p$-values $<0.001$ ) and the estimated standardized regression coefficient for the effect of SPQ total on neglect was $0.28(p<0.001)$ (See Fig. 1).

The bootstrapping confidence intervals of all paths, which test the mediating factor of childhood neglect between SPT and depression, did not include zero (see Table 4) thus indicating that childhood neglect is a significant mediator in the relationship between SPT and depression.

The fit indices $(\mathrm{GFI}=0.998$, AGFI $=0.992$, $\mathrm{RMSEA}=$ 0.031 and $C F I=0.997)$ indicated satisfactory model fits. However, although the Chi-squared $\left(x^{2}\right)$ test reported a $p<0.05$ indicating that the model was not acceptable, the $\chi^{2}$ test is sensitive to large sample sizes and so other suitable statistics should be considered.

\section{Discussion}

In this study we explored factors that impact the relationship between APT/SPT and depression in a large sample of college students. To our knowledge, this is the first study to examine childhood neglect as a mediating factor. The results will add to the

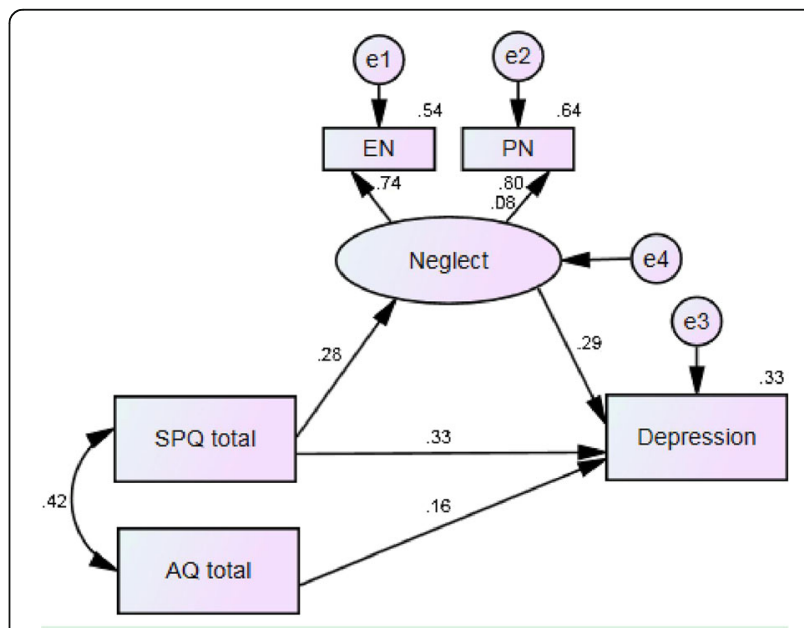

Fig. 1 Neglect mediates the relationship between SPQ and depression 
Table 4 Mediation analysis examining the indirect effect of neglect between SPQ total and depression

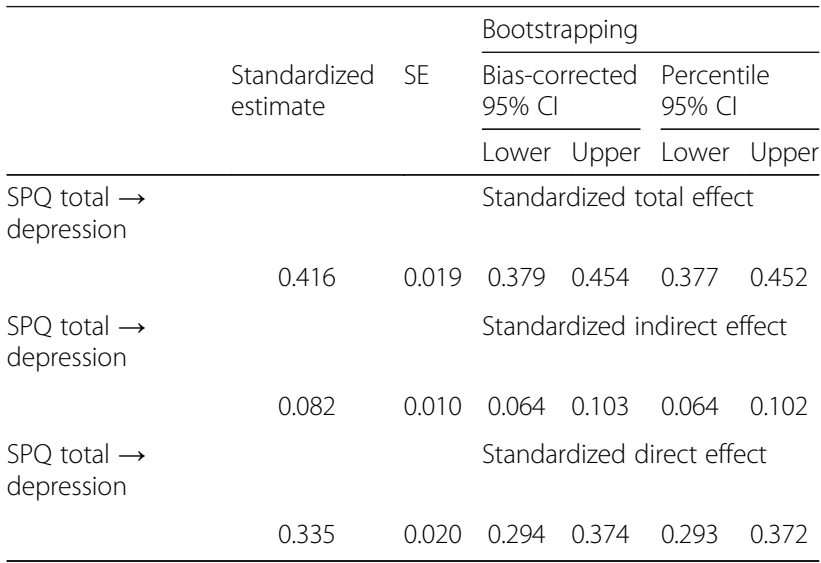

current understanding of the relationship between $\mathrm{APT} / \mathrm{SPT}$ and depression.

The current study found that APT and SPT are independent predictors of depression symptoms, which is in agreement with previous literature. For example, Fonseca-Pedrero et al. [14] found that SPT and subclinical depressive symptoms were highly overlapping phenomena among the nonclinical adolescent population. Shi et al. [43] found that participants with higher SPQ scores $(\geq 36)$ also scored higher on depressive symptoms compared to those with low SPQ scores $(\leq 10)$. Xu et al. [44] found that APT also positively predicted depression symptoms.

Additionally, in adult patients with mood disorders, Matsuo et al. [45] found that APT were associated with depression symptom severity. As participants with autistic traits cannot easily adapt to the changing environment, they are perhaps more vulnerable to depression symptoms [46]. For participants with schizotypal traits, many prior studies have found that positive and negative SPT symptoms increase depression symptoms [14]. Moreover, SPT can play a detrimental role in cognitive function [47], thus leading to an increased depression [48].

HPA-axis dysregulation has previously been reported in clinical patients with SPD and APD $[5,6]$. A dysregulation of the HPA-axis can lead to a cortisol abnormality [6], which can in turn increase depression [6]. Therefore, the underlying cause of depression symptoms associated with APT and SPT may be similar.

From a genetic perspective, Gong et al. [49] reported that HTR2A gene T102C polymorphism is associated with autistic-like behavior in healthy individuals; Jokela et al. [50] also found that HTR2A gene $\mathrm{T} 102 \mathrm{C}$ polymorphism may affect depression symptoms through gene-environment interactions. It is therefore possible that APT and depression symptoms may have a common underlying genetic cause. Similarly, COMT Val158Met significantly influences schizotypal trait scores among healthy people [51] and plays a role in the susceptibility to depressive symptoms among postmenopausal women [52].

Consistent with our hypothesis stated earlier in this paper and in previous research, among all childhood maltreatments, neglect was the strongest predictor for depressive symptoms. Hermenau et al. [22] found that in a sample of orphans the experience of neglect (but not abuse) was correlated with depression severity. A recent meta-analysis also reported that neglect is a stronger predictor of depression than either sexual or physical abuse [53].

Interestingly, recent research found that neglect (as an childhood stress) can affect gene expression, DNA transcription and translation [54, 55], which may in turn affect some genes related to depression, as described earlier.

After controlling for neglect, the relationships between APT/SPT and depression remained significant thus indicating that neglect does not account for these relationships. However, upon further analysis, we found that childhood neglect mediated the relationship between SPT and depression.

To our knowledge, this is the first report demonstrating how the link between SPT and depression is mediated by neglect. In agreement with previous research [29], the current study found that SPT were positively correlated with childhood neglect. In fact, it has previously been shown that a variety of disabilities may increase the susceptibility of childhood abuse and neglect $[24,26]$. In addition, these results also suggest that the incidence of neglect must be factored into the treatment of children with SPT.

Childhood neglect can increase depression [56]. While our findings may give some insight into the relationship between SPT and depression, other factors such as heredity and the interaction between environment and heredity should be further explored [57-59].

Although there was a trend for APT to be positively correlated with neglect in the correlational analysis, there was no relationship between APT and neglect in the mediation analysis. One possible explanation for this discrepancy is the difference in statistical methods. The correlation analysis (a single factor analysis) was relatively unstable compared to mediation analysis.

While the current study provides significant insight into the relationships between ATP/SPT and depression, there are some limitations that must be considered. First, whether the results of the current study are applicable to a clinical population is unknown, since all participants were healthy college students. Thus, future 
research should include clinically diagnosed SPD and ASD patients.

Second, the current study only explored childhood mental factors affecting the relationships between APT/ SPT and depression. Future studies should include genetic effects on the relationships between APT/SPT and depression [10] as well as the effects of the interaction between genetics and environment.

Third, since the participants were from medical and general colleges that tend to have more female than male students, there was a large discrepancy between the number of male and female participants in the current study.

Fourth, data were collected through self-report questionnaires, which are prone to bias since participants wish to provide socially desirable responses. Specifically, recall bias is inherent to questions on the CTQ relating to the recall of childhood traumas.

Fifth, the Zung self-rating depression scale is wellvalidated in the measurement of depression symptoms [37]. However, the validity of the questionnaire in the measurement of depression trait is unclear. Therefore, future research should use a depression trait scale to further explore the association between $\mathrm{ATP} / \mathrm{SPT}$ and depression.

Sixth, SPT and depression can confound one another. For example, anhedonia-like characteristics are shared between SPT and depression and as such these factors are difficult to dissociate.

Seventh, this study is a cross-section study, and therefore, causal relationships can not be determined.

Eighth, relational data, such as general psychopathology in the family, which may increase risk for general psychopathology were not gathered in the current study. In future studies, we will further test the mediating effects of neglect in the relationship between SPT and depression controlling for psychopathology in the family.

Lastly, although CTQ is a commonly accepted scale for assessing childhood abuse and neglect [35], some recent studies have found that CTQ may lack structural invariance in cross-cultural adaptations [60].

\section{Conclusions}

To our knowledge, this is the first study to examine childhood neglect as a mediating factor in the relationship between APT/SPT and depression. Among types of childhood maltreatment, neglect was the strongest predicting factor for depression. Neglect did not account for the relationship between APT/SPT and depression but was a strong mediating factor between SPT and depression.

\section{Abbreviations}

APT: Autistic personality traits; ASD: Autism spectrum disorder; HPA: Hypothalamic-pituitary-adrenal; SPD: Schizophrenia spectrum disorder; SPT: Schizotypal personality traits
Acknowledgements

None.

\section{Funding}

This study was supported by the Hunan Provincial Innovation Foundation for Postgraduate (No. CX2016B062, Jianbo Liu).

\section{Availability of data and materials}

The datasets used and/or analysed during the current study are available from the corresponding author on reasonable request.

\section{Authors' contributions}

JL was primarily responsible for manuscript writing, analysis and interpretation of data. JG participated in the conception and design of the study and acquisition of data. GN contributed to data analysis, interpretation of data, manuscript revisions, and intellectual content. YH contributed to the acquisition of data, manuscript revisions, and intellectual content. BX contributed to the acquisition of data, manuscript revisions and intellectual content. YS contributed to the acquisition of data, manuscript revisions, and intellectual content. XL contributed to the conception and design of the study, interpretation of data, manuscript revisions and intellectual content. All authors read and approved the final manuscript

\section{Ethics approval and consent to participate}

The Ethics Committee of the Second Hospital of Hunan University of Chinese Medicine approved the study. Table 1 displays the demographic characteristics of the participants. All participants provided written informed consent.

Consent for publication

Not applicable.

\section{Competing interests}

The authors declare that they have no competing interests.

\section{Publisher's Note}

Springer Nature remains neutral with regard to jurisdictional claims in published maps and institutional affiliations.

\section{Author details}

${ }^{1}$ Mental Health Institute of The Second Xiangya Hospital and Key Laboratory of Psychiatry and Mental Health of Hunan Province, The Central South University, Changsha 410000, China. ²Department of Applied Psychology, Traditional Chinese Medicine University of Hunan, Changsha 410208, China.

${ }^{3}$ School of Public Health, Guangxi Medical University, Nanning 530000, China.

Received: 24 November 2016 Accepted: 15 October 2017

Published online: 25 October 2017

\section{References}

1. Bitsika V, Sharpley CF, Andronicos NM, Agnew LL. Prevalence, structure and correlates of anxiety-depression in boys with an autism spectrum disorder. Res Dev Disabil. 2016:49-50:302-11.

2. Onwuameze OE, Uga A, Paradiso S. Longitudinal assessment of clinical risk factors for depression in schizophrenia spectrum disorders. Ann Clin Psychiat. 2016;28(3):167-74

3. Matson JL, Williams LW. Depression and mood disorders among persons with autism spectrum disorders. Res Dev Disabil. 2014;35(9):2003-7.

4. Matson JL, Nebel-Schwalm MS. Comorbid psychopathology with autism spectrum disorder in children: an overview. Res Dev Disabil. 2007;28(4):341-52.

5. Altamura AC, Boin F, Maes M. HPA axis and cytokines dysregulation in schizophrenia: potential implications for the antipsychotic treatment. Eur Neuropsychopharmacol. 1999;10(1):1-4.

6. Sharpley CF, Bitsika V, Andronicos NM, Agnew LL. Further evidence of HPAaxis dysregulation and its correlation with depression in autism Spectrum disorders: data from girls. Physiol Behav. 2016;167:110-7.

7. Rai V. Association of methylenetetrahydrofolate reductase (MTHFR) gene C677T polymorphism with autism: evidence of genetic susceptibility. Metab Brain Dis. 2016;31(4):727-35.

8. Sayadi MA, Achour O, Ezzaher A, Hellara I, Omezzine A, Douki W, Bousslama A, Gaha L, Najjar MF. CT genotype of 5,10-methylenetetrahydrofolate 
reductase (MTHFR) C677T polymorphism is protector factor of major depressive disorder in the Tunisian population: a case control study. Ann General Psychiatry. 2016;15:18.

9. Gonzalez-Castro TB, Hernandez-Diaz Y, Juarez-Rojop IE, Lopez-Nanvaez ML, TovillaZarate CA, Fresan A. The role of a Catechol-O-Methyltransferase (COMT) Val158Met genetic polymorphism in schizophrenia: a systematic review and updated meta-analysis on 32,816 subjects. NeuroMolecular Med. 2016;18(2):216-31.

10. Liu J, Wu J, Nie G, Zeng W, Zhang M, Tan L, Fu P, Yang L. Catechol-Omethyl transferase SNP rs4680 influence risk of mood disorder: a metaanalysis. Int J Clin Exp Med. 2016;9(6):6152-65.

11. Romero-Martinez A, Moya-Albiol L, Vinkhuyzen AA, Polderman TJ. Genetic and environmental contributions to the inverse association between specific autistic traits and experience seeking in adults. Am J Med Genet Part B Neuropsychiatr Genet. 2015;171(8):1190-1197.

12. Meehl PE. Schizotaxia, schizotypy, schizophrenia. Am Psychol. 1962;17(12):827.

13. Mealey A, Abbott G, Byrne LK, McGillivray J. Overlap between autistic and schizotypal personality traits is not accounted for by anxiety and depression. Psychiatry Res. 2014;219(2):380-5.

14. Fonseca-Pedrero E, Paino M, Lemos-Giraldez S, Muniz J. Schizotypal traits and depressive symptoms in nonclinical adolescents. Compr Psychiatry. 2011;52(3):293-300.

15. Liew SM, Thevaraja N, Hong RY, Magiati I. The relationship between autistic traits and social anxiety, worry, obsessive-compulsive, and depressive symptoms: specific and non-specific mediators in a student sample. J Autism Dev Disord. 2015;45(3):858-72.

16. Towbin KE, Pradella A, Gorrindo T, Pine DS, Leibenluft E. Autism spectrum traits in children with mood and anxiety disorders. J Child Adolesc Psychopharmacol. 2005;15(3):452-64.

17. Lin L, Du Q, Hu N, Jia G, Wang P. Study on the correlation between childhood neglect and coping styles of middle school students. CJCHC OCT. 2012;20(10):890-2.

18. Afifi TO, MacMillan HL, Boyle M, Taillieu T, Cheung K, Sareen J. Child abuse and mental disorders in Canada. CMAJ. 2014;186(9):E324-32.

19. Fang $X$, Fry DA, Brown DS, Mercy JA, Dunne MP, Butchart AR, Corso PS, Maynzyuk K, Dzhygyr Y, Chen Y, et al. The burden of child maltreatment in the East Asia and Pacific region. Child Abuse Negl. 2015;42:146-62.

20. Kim EY, Park J, Kim B. Type of childhood maltreatment and the risk of criminal recidivism in adult probationers: a cross-sectional study. BMC Psychiatry. 2016;16:294

21. Li M, D'Arcy C, Meng X. Maltreatment in childhood substantially increases the risk of adult depression and anxiety in prospective cohort studies: systematic review, meta-analysis, and proportional attributable fractions. Psychol Med. 2016;46(4):717-30.

22. Hermenau K, Eggert I, Landolt MA, Hecker T. Neglect and perceived stigmatization impact psychological distress of orphans in Tanzania. Eur J Psychotraumatol. 2015;6:28617.

23. Grassi-Oliveira R, de Azevedo Gomes CF, Stein LM. False recognition in women with a history of childhood emotional neglect and diagnose of recurrent major depression. Conscious Cogn. 2011;20(4):1127-34.

24. Bleil Walters J, Hughes TL, Sutton LR, Marshall SN, Crothers LM, Lehman C, Paserba D, Talkington V, Taormina R, Huang A. Maltreatment and depression in adolescent sexual offenders with an autism spectrum disorder. J Child Sex Abuse. 2013;22(1):72-89.

25. Sullivan PM, Knutson JF. Maltreatment and disabilities: a population-based epidemiological study. Child Abuse Negl. 2000;24(10):1257-73.

26. Sobsey R. Violence and abuse in the lives of people with disabilities: The end of silent acceptance?[M]. Baltimore, MD: Paul H Brookes Publishing; 1994

27. Esterberg ML, Trotman HD, Brasfield JL, Compton MT, Walker EF. Childhood and current autistic features in adolescents with schizotypal personality disorder. Schizophr Res. 2008;104(1-3):265-73.

28. Holmboe K, Rijsdijk FV, Hallett V, Happe F, Plomin R, Ronald A. Strong genetic influences on the stability of autistic traits in childhood. J Am Acad Child Adolesc Psychiatry. 2014;53(2):221-30.

29. Berenbaum H, Valera EM, Kerns JG. Psychological trauma and schizotypal symptoms. Schizophr Bull. 2003;29(1):143-52.

30. Bernstein DP, Ahluvalia T, Pogge D, Handelsman L. Validity of the Childhood Trauma Questionnaire in an adolescent psychiatric population. J Am Acad Child Adolesc Psychiatry. 1997;36(3):340-48.

31. Baron-Cohen S, Wheelwright S, Skinner R, Martin J, Clubley E. The autismspectrum quotient $(\mathrm{AQ})$ : evidence from Asperger syndrome/high- functioning autism, males and females, scientists and mathematicians. J Autism Dev Disord. 2001;31(1):5-17.

32. Zhang L, Sun Y, Chen F, Wu D, Tang J, Han X, Ye J, Wang K. Psychometric properties of the autism-Spectrum quotient in both clinical and non-clinical samples: Chinese version for mainland China. BMC Psychiatry. 2016;16:213.

33. Raine A. The SPQ: a scale for the assessment of schizotypal personality based on DSM-III-R criteria. Schizophr Bull. 1991;17(4):555-64.

34. Chen WJ, Hsiao CK, Lin CC. Schizotypy in community samples: the threefactor structure and correlation with sustained attention. J Abnorm Psychol. 1997;106(4):649-54.

35. Bernstein DP, Fink L, Handelsman L, Foote J, Lovejoy M, Wenzel K, Sapareto E, Ruggiero J. Initial reliability and validity of a new retrospective measure of child abuse and neglect. Am J Psychiatry. 1994;151(8):1132-6.

36. WQ F, Yao SQ, HH Y, Zhao XF. Initial reliablity and valiadity of childhoood truama questinnaire(CTQ-SF) apllied in Chinese college students. Chin J Clin Psychol. 2005;13(1):40-2.

37. Zung WWK. A self-rating depression scale. Arch Gen Psychiatry. 1965;12(1):63-70.

38. Zhang DX, Luo JH, Peng LZ, Yu Z. Factor analysis on survey results of the self rating depression scale(SDS) in students. J Kunming Med Univ. 2012;5(33):61-3.

39. Mackinnon DP, Lockwood CM, Williams J. Confidence limits for the indirect effect: distribution of the product and Resampling methods. Multivar Behav Res. 2004;39(1):99.

40. Goodall K, Rush R, Grunwald L, Darling S, Tiliopoulos N. Attachment as a partial mediator of the relationship between emotional abuse and schizotypy. Psychiatry Res. 2015;230(2):531-6.

41. Hu L, Bentler PM. Cutoff criteria for fit indexes in covariance structure analysis: conventional criteria versus new alternatives. Struct Equ Model Multidiscip J. 1999;6(1):1-55.

42. Bentler PM. Comparative fit indexes in structural models. Psychol Bull. 1990; 107(2):238-46.

43. Shi YF, Wang Y, Cao XY, Wang Y, Wang YN, Zong JG, Xu T, Tse WW, Hsi XL, Stone WS, et al. Experience of pleasure and emotional expression in individuals with schizotypal personality features. PLoS One. 2012;7(5):e34147.

44. Xu W, Fu Z, Wang J, Zhang Y. Relationship between autistic traits and hoarding in a large non-clinical Chinese sample: mediating effect of anxiety and depression. Psychol Rep. 2015;116(1):23-32.

45. Matsuo J, Kamio Y, Takahashi H, Ota M, Teraishi T, Hori H, Nagashima A, Takei R, Higuchi T, Motohashi N, et al. Autistic-like traits in adult patients with mood disorders and schizophrenia. PLoS One. 2015;10(4):e0122711.

46. Hoekstra RA, Bartels M, Hudziak JJ, Van Beijsterveldt TC, Boomsma DI. Genetic and environmental covariation between autistic traits and behavioral problems. Twin Res Hum Genet. 2007;10(6):853-60.

47. Noguchi $\mathrm{H}$, Hori $\mathrm{H}$, Kunugi $\mathrm{H}$. Schizotypal traits and cognitive function in healthy adults. Psychiatry Res. 2008;161(2):162-9.

48. Kim BJ, Nakaoka S, Underwood C. The impacts of social support and cognitive function on depression among community-dwelling older Japanese Americans. Soc Work Public Health. 2016:1-12.

49. Gong P, Liu J, Blue PR, Li S, Zhou X. Serotonin receptor gene (HTR2A) T102C polymorphism modulates individuals' perspective taking ability and autisticlike traits. Front Hum Neurosci. 2015:9:575.

50. Jokela M, Lehtimaki T, Keltikangas-Jarvinen L. The influence of urban/rural residency on depressive symptoms is moderated by the serotonin receptor 2A gene. Am J Med Gen Part B Neuropsychiatr Genet. 2007;144b(7):918-22.

51. Ma X, Sun J, Yao J, Wang Q, Hu X, Deng W, Sun X, Liu X, Murray RM, Collier $D A$, et al. A quantitative association study between schizotypal traits and COMT, PRODH and BDNF genes in a healthy Chinese population. Psychiatry Res. 2007;153(1):7-15.

52. Rozycka A, Slopien R, Slopien A, Dorszewska J, Seremak-Mrozikiewicz A, Lianeri M, Maciukiewicz M, Warenik-Szymankiewicz A, Grzelak T, Kurzawinska $G$, et al. The MAOA, COMT, MTHFR and ESR1 gene polymorphisms are associated with the risk of depression in menopausal women. Maturitas. 2016;84:42-54.

53. Infurna MR, Reichl C, Parzer P, Schimmenti A, Bifulco A, Kaess M. Associations between depression and specific childhood experiences of abuse and neglect: a meta-analysis. J Affect Disord. 2016;190:47-55.

54. Bordner KA, George ED, Carlyle BC, Duque A, Kitchen RR, Lam TT, Colangelo CM, Stone KL, Abbott TB, Mane SM, et al. Functional genomic and proteomic analysis reveals disruption of myelin-related genes and translation in a mouse model of early life neglect. Front Psychiatry. 2011;2:18. 
55. Montalvo-Ortiz JL, Gelernter J, Hudziak J, Kaufman J. RDoC and translational perspectives on the genetics of trauma-related psychiatric disorders. Am J Med Genet Part B Neuropsychiatr Genet. 2016;171b(1):81-91.

56. Schilling C, Weidner K, Brahler E, Glaesmer H, Hauser W, Pohlmann K. Patterns of childhood abuse and neglect in a representative German population sample. PLoS One. 2016;11(7):e0159510.

57. Jones RM, Cadby G, Blangero J, Abraham LJ, Whitehouse AJ, Moses EK. MACROD2 gene associated with autistic-like traits in a general population sample. Psychiatr Genet. 2014;24(6):241-8.

58. Rijlaarsdam J, van IMH VFC, Jaddoe VW, Felix JF, Tiemeier H, BakermansKranenburg MJ. Prenatal stress exposure, oxytocin receptor gene (OXTR) methylation and child autistic traits: the moderating role of OXTR rs53576 genotype. Autism Res. 2017;10(3):430-38.

59. Yasuda Y, Hashimoto R, Ohi K, Fukumoto M, Umeda-Yano S, Yamamori H, Okochi T, Iwase M, Kazui H, Iwata N, et al. Impact on schizotypal personality trait of a genome-wide supported psychosis variant of the ZNF804A gene. Neurosci Lett. 2011:495(3):216-20.

60. Innamorati M, Erbuto D, Venturini P, Fagioli F, Ricci F, Lester D, Amore M, Girardi P, Pompili M. Factorial validity of the childhood trauma questionnaire in Italian psychiatric patients. Psychiatry Res. 2016;245:297-302.

\section{Submit your next manuscript to BioMed Central} and we will help you at every step:

- We accept pre-submission inquiries

- Our selector tool helps you to find the most relevant journal

- We provide round the clock customer support

- Convenient online submission

- Thorough peer review

- Inclusion in PubMed and all major indexing services

- Maximum visibility for your research

Submit your manuscript at www.biomedcentral.com/submit 